\title{
Person Centered Healthcare and Clinical Research: The Necessity of an Evolutionary Hierarchy of Knowing and Doing
}

\author{
Peter Wyer MD ${ }^{\mathrm{a}}$ \& Michael Loughlin $\mathrm{PhD}^{\mathrm{b}}$ \\ a Associate Professor of Medicine, Columbia University Medical Center, NYC, USA \\ b Professor of Applied Philosophy \& Co-Director, European Institute for Person Centred Health \& Social Care, University of \\ West London, London, UK
}

\begin{abstract}
Effective person-centred care requires recognition of the personhood not only of patients but of practitioners. This chapter explores the consequences of this recognition for major debates in medical epistemology, regarding clinical reasoning and the relationship between research and practice. For too long these debates have been dominated by false dichotomies subjectivity versus objectivity, judgement versus evidence, reason versus emotion. Based on flawed understandings of such core concepts as "objectivity" and "engagement", this distorted dissection of the subject-object relationship has served to depersonalise practice. The costs of this depersonalisation include over-regulation and micromanagement of healthcare processes by administrators and payers at the same time that information from clinical research remains under-utilized and the personhood of patients' risks being ignored.

Science is a human practice, founded in a broader conception of human reasoning, ontologically dependent on human beings living and engaging with the world in social, emotional and ethical contexts. After looking at different conceptions of epistemic hierarchies and their uses in the analysis and evaluation of reasoning in a range of practice contexts, we propose a "nested hierarchy" that effectively turns upside-down the flawed evidence hierarchies that have helped to depersonalise care. T.S. Eliot's “wisdom, knowledge, information” scheme (to which we add “data” below "information”) provides a model for a person-centred epistemic hierarchy. This crucial, person-centred inversion represents levels of awareness that characterize more or less developed thinking and judgment on the part of the particular practitioner.
\end{abstract}

\section{Keywords}

Engagement, epistemic hierarchies, evidence, evidence-based medicine, judgement, knowledge, person-centered care, personhood, reasoning, science, wisdom

\section{Correspondence address}

Dr. Peter Wyer. E-mail: pwyer1@gmail.com

Accepted for publication: 17 November 2019

\section{Introduction}

"The clinical encounter is an interaction between persons.” Stephen Henry [1].

Who is "the person" in person-centered healthcare (PCH)? While many authors explain PCH and its importance by focusing on what it means to treat "the patient" as a person, [2-4] others note the significance of recognizing the personhood of practitioners [1,5,6]. This chapter explores the consequences of this recognition for major debates in medical epistemology, regarding clinical reasoning and the relationship between research and practice.

For many years, medical epistemology has been dominated by an epistemic hierarchy thought to be "objective" - but what does this term mean? There are numerous senses of the term "objective" that render objectivity an indispensable aspect of responsible research and clinical decision-making. If we predicate the term "objective" primarily of a person (rather than an impersonal method) and if, by an "objective” person we mean someone who puts aside prejudice, thinks critically, questions her own assumptions and searches for the truth, then it is of course palpably absurd to deny the importance of objectivity in all rational thought, including clinical reasoning. But the term has a long history, and its current usage - in particular its status as an antonym of the term "subjective" - is shaped by assumptions that are so fundamental in nature that they typically escape critical attention. And yet, these assumptions have framed the discussion of medical epistemology in this century [7-9]. The conceptual framework shaping our thinking about objectivity has led us to focus on a hierarchy of knowledge designed to delimit the role of "subjective" or "personal" judgment. Attempts to "de-emphasise" intuition, the practitioner's personal experience, tacit and contextspecific knowledge [11-15], and to elevate such skills as 
"efficient literature searching and the application of formal rules of evidence evaluating the clinical literature”, are motivated by a concern to see reasoning and practice based increasingly on "methodologically sound research" and "scientific principles" [11] whose vindication is, precisely, that they are untainted by the personal and subjective factors that we rely on in our everyday interactions with other people [9].

Given that practitioners are, in fact, persons, and rely on such "subjective" factors as tacit awareness, engagement and empathy [1,6] to understand the real people with whom they must interact and who they aim to assist, discussions have focused on how to "integrate" the subjective, cultural and personal factors of human knowledge into models of clinical practice that nonetheless place objective evidence at the top of a presumed epistemic hierarchy [16-18].

The problems with this integration project (or rather, re-integration project, since it only becomes necessary to "integrate" these features once a theoretical separation has been performed) have led some authors to reject the idea of a hierarchy altogether, and to call for a "horizontal epistemology” for clinical practice, one which "collapses epistemic hierarchies into horizontally ordered libraries of clinical knowledge sources, from which 'library' the wise clinician will need to draw when considering the unique personal circumstances of the individual clinical case and making decisions with him/her" [10]. Here, we argue that the notion of an epistemic hierarchy is indeed indispensable, but it needs to be one that reflects the concerns of these critics by considering how individual practitioners can develop their understanding so as to practice more wisely. T.S. Eliot's "wisdom, knowledge, information" scheme, to which we would add "data” below “information”, represents a model for a person-centered epistemic hierarchy. This is not a hierarchy of "impersonal" knowledge, but rather a representation of levels of awareness that characterize more or less developed thinking and judgment on the part of the particular practitioner.

Far from 'de-emphasizing' personal judgment, or relegating it to a lower form of evidence than supposedly 'impersonal' sources, we need "an approach to medical epistemology that places the concept of judgment at the centre, and treats the (primarily moral) project of how to cultivate good judgement as its central concern” [8].

\section{Research, paradigms and practice}

After centuries of development of the health professions dominated by what is commonly known as the 'medical model', the concept of health care and the appreciation of the need to shift the healthcare paradigm from 'care of the patient' to 'services to the person' are remarkably recent in origin. Donald Berwick summarizes the trajectory of this evolution in a recent opinion piece in the Journal of the American Medical Association [19]. He suggests that the history we are addressing can be conceptualized as traversing three eras, the first of which extended well into this century from antiquity and revolved around the image of the medical professional as a (usually) male, dedicated, ethically bound but ultimately paternalistic shepherd overseeing the health needs of his patients. Era 2, characterized by the flowering of clinical and health services research, saw the emergence of the need for systems development, standardization of services, regulation of practice and outcome measurements, all in response to the increasing complexity of the healthcare environment and the emergence of third party payers as essential stakeholders in the system. Berwick [19] perceives that the processes of standardization, regulation and measurement have reached and surpassed a point at which they cease to become assets and begin to become major burdens to the efficiency and effectiveness of the system. He proposes the necessity for an "Era 3", in which regulation and measurement are relaxed in favor of a shift in incentives and, among other changes, an emphasis on patient empowerment and autonomy [20].

The call for a more user-friendly, consumer-oriented and humanistic healthcare environment takes place amidst a proliferation of buzz phrases that correspond to sometimes very different outlooks and perspectives. These include 'patient-centered care', 'relationship centered care', 'person-centered care' and 'whole person care'. In most cases, the corresponding constructs are, at best, loosely defined and furthermore tend to ignore the role of the practitioner as a vital partner in healthcare decisionmaking. When an appealing new conceptual framework is advanced and defined only in the most generic, rhetorically appealing terms, the resulting buzz phrase is prone to multiple interpretations and applications whose underlying content and motivations may differ widely [21-23]. This liability is particularly manifest when the concept in question is widely taken up and disseminated. Tanenbaum demonstrated that the label 'patient centered care' has come to refer to at least four different dimensions of healthcare [24]. Indeed, when the uptake of a popular label is sufficiently broad and the corresponding descriptors sufficiently vague, distinctions may break down altogether and a semantic 'unity of opposites' may emerge. Hence EBM, a movement focused on the importance of research literacy in medical education [25], has been portrayed by some of its advocates as the preferred label to be used in connection with humanistic, patient empowered healthcare [26].

The jumble of terms, slogans and labels pertaining to care of the person that populates the recent healthcare literature reflects a confusion on a much deeper level, one that calls for attention to the underlying epistemological and philosophical constructs. It also relates to a pressing dilemma facing healthcare today, namely the gap that separates the clinical research enterprise from the domain of clinical practice. A premise of this chapter is that our inquiry corresponds to this extremely high stakes issue. The issue is not an abstract one. It is a matter of the relationship of healthcare, as delivered to actual populations and to actual individual people by actual healthcare professionals and their ancillary staff members, to the products of clinical research and to the expanding wellspring of biomedical knowledge. To address it, we need to ask questions such as "what does it mean to use 
information from research in the course of healthcare practice and policymaking?"

Failure to translate the results of research into useful applications in practice is not unique to healthcare. A 2012 US National Science Foundation report summarized the findings of a select committee on the use of social sciences research in public policy. It concluded that the ability to demonstrate consistent use of research in practice is problematic and that no progress could be demonstrated since the report of a similarly tasked NSF committee report from 30 years before [27]. Within healthcare, a relatively straightforward, if imperfect, metric for assessing use of research is provided by the extent to which clinical practice conforms to the recommendations of published evidencebased guidelines. Surveys have consistently reported the adherence in practice to clinical guideline recommendations, including those supported by scientific research, to be marginally over $50 \%$ at best [28-32]. As a result of such observations, a veritable cottage industry seeking 'fixes' for the dilemma has emerged. Knowledge translation and implementation science constitute practical disciplines supported by research agendas aimed at the development and facilitation of tools and methods capable of bridging the research-to-practice gap. These emergent disciplines encompass a wide range of perspectives and conceptual outlooks which vary across different healthcare disciplines [33]. Unfortunately, successes attributable to these efforts have been few and far between. For example, despite internationally coordinated efforts to develop and validate standards for patient-centered decision support tools, clinicians refrain from utilizing them [34] and, even when they do, their use proves to be only marginally effective [35].

The governing premise of this chapter is that realization of Berwick's vision of an "Era 3" in healthcare, achievement of a healthcare of the person, and fruitful closure of the gap between research, policy and practice, all require conceptual and practical closure of a gap that lies even deeper. Western philosophical, scientific and social systems are characterized by a fundamental dualism [36-38]. Though the term is most closely associated with Descartes $[39,40]$, the history of this conceptual divide predates his work. This dualism is conditioned by our deeprooted, historical understanding of the relation between knowing subjects and the known world, and is reflected in a diverse range of philosophies. Plato reveals it in his tripartite division of the soul, setting Reason above appetites, emotions and imagination in any true pursuit of knowledge [41]. Aristotle reveals it in his Rhetoric (3.1.1404a3-8) [42] where he says we should "aim at nothing more in a speech than not to give pain or delight. For it is just that a case be fought with the facts themselves, so that everything else outside of proving them is superfluous." Descartes entrenches the same dichotomies for the modern age: it is the subject, with his faulty judgments, who must 'get out of the way' if the object in itself is to be grasped [43]; similarly, for Locke and Hume, though these two come from the opposite side of the Rationalist/Empiricist divide to their predecessor, Descartes [44,45]. In all, there is cross-party agreement that knowledge-seeking is an enterprise only for the subject in the abstract, his objective reason divorced from all other features of his humanity, including valuejudgments, intuitions, feelings and all things "personal" [9].

Recognition of the relevance of the dualistic dilemma within Western philosophy to resolving the multi-level fragmentation of the healthcare enterprise abounds in the biomedical literature [46-48]. In what follows, we will attempt to establish the relevance of the long-established opposition between subject and object to the ways in which medical research is characterized, practiced and ultimately applied. We hope to identify how the historically misconstrued opposition of subject and object impacts on the provision of a proper and adequate epistemology of person-centered healthcare. Specifically, we will show the relevance of this issue to a central requirement of $\mathrm{PCH}$, that is, the importance of a relationship-centered understanding of healthcare interactions in which practitioners, patients, families, significant others and the full array of health caretakers, play crucial and irreducible roles in the process. We will identify the necessity to such an understanding of what we will term an 'evolutionary hierarchy of information and knowledge'. We will briefly illustrate these concepts drawing on established precedents within the healthcare arena of non-dualistic solutions to the quest for improved, person-centered healthcare.

\section{Obstructive Oppositions}

To enter the world of discussion and debate pertaining to the philosophy of medicine is to risk becoming immersed in an ocean of 'isms', trends, proposed constructs and ideologies. For the purposes of this discussion, we need to avoid entanglement in philosophical intricacies so as to bring clarity to the points most relevant to healthcare. At the same time, the historical conflict between empiricism and rationalism is vital to a serious consideration of the unsatisfying gap between clinical research and healthcare practice. It is a conflict that has undergone multiple iterations and resurgences going back to antiquity [40].

Empiricism has no doubt been the greatest influence on the modern conception of science, scientific method and, by extension, the biomedical sciences and the conceived relationship between medical practitioner and patient. In itself, empiricism simply consists in a thesis which posits sense experience as the primary source of knowledge. Reason, too, has its place in the development of a body of knowledge, but its role is deemed to be secondary: reason sets to work once sensory information has been gathered. Sense experience provides the 'raw materials' from which reason extrapolates. To clarify, to make use of empirical evidence is not to commit oneself to the epistemic premise of empiricism: the rationalist may stick his hand out of the window to see if it is raining, without thereby compromising his philosophical position. What differentiates the rationalist from the empiricist is the belief in the primacy of reason over sense experience: reason supplies us with a framework of principles which help us to make sense of our experience. Thus, just as a rationalist 
can look to see if there is evidence of rain, an empiricist can acknowledge the importance of human reasoning, and can accordingly be a mathematician or logician without abandoning his empiricist premise. The point of difference between these philosophic traditions rests only on the primacy of sense over reason, or of reason over sense.

By the time of Locke, the battle was well underway for the 'soul' of science, with the British empiricist school contesting the rationalist, Cartesian conception of science as subject to foundational principles unearthed by philosophers. Locke abruptly reverses this 'power relation', stating: "It is ambition enough to be employed as an under-labourer to the sciences, clearing the ground a little, and removing some of the rubbish which lies in the way to knowledge" [44]. Locke had in mind the great advances of such as "the incomparable Mr Newton", whose system could not have advanced under the fetters of Cartesian rationalism, and so, historically, with the rising star of Newton, the empirical conception of science, shaped by Locke, came to predominate.

The story does not end there though, for after Locke's brand of scientific realism came Berkeley who forged the link between empiricism and idealism, whereupon Hume intervened to draw out the potentials for skepticism that logically unfold from a strict empiricist starting point [45,49]. For Hume, empirical observation is the only source of knowledge, and reason is no more (and no less) than logical deduction. So the realm of the known is strictly limited to propositions that either report observations or follow deductively from such propositions - and Hume was very clear that many of our everyday, common-sense claims do not follow strictly from empirical observation [45].

Hume's influence on the developing conception of science is no less than was Locke's and is felt particularly through the rise of the logical positivist movement in the early $20^{\text {th }}$ Century. The application of Hume's strict empiricism to understanding the methods of science was to become the hallmark of the logical positivist approach. It resulted in that school's rigid adherence to multiple conceptual dichotomies: fact vs. value, object vs. subject, reason vs. emotion, science vs. art. These oppositions have undoubtedly generated problems for activities that at once strive to be 'scientific' and yet also deal with the distinctively human $[8,9]$.

There is a general question to be asked as to whether any substantial body of knowledge, especially one with human-oriented practical applications, can be built upon a foundation that leans so readily towards skepticism and it is this insight that has prompted many credible figures, such as Noam Chomsky [50], to turn towards rationalism in some form. Nevertheless, the problems we face in constructing a coherent account of research, and its relationship to human activity, go well beyond the rationalist/empiricist schism: both sides are affected by the same construction of the relationship between subject and object that permeates the thinking of Plato and Aristotle, of Locke and Descartes, of positivism, logical positivism, and their many critics [7-9]. It was Descartes' view that reason could generate substantive knowledge of the real world that presented, for him, the solution to otherwise intractable skeptical problems [43]. Hume's far more limited account of what reason could do led him to be far more skeptical precisely because he treated knowledge as generated purely by 'observation plus deduction' [45]. What both thinkers have in common is a failure to consider any other factors as possible generators of real, substantive knowledge - each takes it as read that being embedded in a social context, engaging with other human beings in empathic relationships, valuing others, feelings and tacit awareness, do not represent 'knowledge proper'.

\section{Muddles}

It is arguable that in many areas of scientific research, advanced theoretical, interpretive and imaginative thinking is essential, such that the assumed dichotomy between "objective" and "subjective" forms of thinking characterized above makes good scientific practice, in many areas of science, impossible $[9,51,52]$. However, it is also possible to argue that medicine is not a science but rather, as Montgomery puts it, "an interpretive practice that relies on clinical reasoning" [53]. Medical education is not scientific training and essentially involves the development of characteristically human, moral capacities [54].

Whether we admit it or not, our position on such matters is determined by assumptions properly characterized as philosophical in nature. The healthcare literature abounds with labels borrowed from philosophical currents and tendencies in the context of defining specific activities and practices. Such labeling is undertaken using relatively loose definitions of the philosophical trends in question. As one example, a loosely framed notion of 'rationalism versus empiricism' in medicine and healthcare considers that the former has to do with the knowledge of mechanisms of disease whereas the latter, empiricism, pertains to the outcomes of individual patients [40]. Such examples reflect at least a latent awareness on the part of their authors of the implicit relevance of philosophy to issues of applied science.

Philosophy is concerned with foundational assumptions and methods. It provides conceptual analysis for clarification and for the avoidance of muddles and unnecessary misunderstandings. It also brings to bear a rich history of ideas which sheds light on the concepts and preconceptions which govern our thinking now. Hence, it is not possible to avoid having, at least implicitly, a philosophical stance of some kind, even though it is possible to avoid making it explicit. By extrapolation, it is not possible to have a 'purely scientific' position, one without implicit philosophical commitments and supported only by scientific evidence. All scientific activity is underpinned by some theory of what science itself actually is and of its proper assumptions, methods and limitations. Such a theory is essential if criteria are to exist that allow the differentiation between science and non-science, or even good and bad science. Recognizing these potentials for muddle, and acknowledging the influence of age-old entrenched philosophical theories, we can move forward in a more productive way to address the relationship between clinical research and person centeredness. 


\section{Alternatives}

So far, all of the philosophical and epistemological trends and tendencies we have considered share one important thing in common: they all treat the world of thought and experience and the world of material things, the knower and the known, as ultimately separate, and even irreconcilably so. Social constructivism provides a framework that can be argued to overcome, or at least sidestep, the difficulties produced by a too rigid opposition of subject and object, of knower and thing known in a fashion that has bearing on the salient issues of medicine and healthcare [55,56]. Social constructivism has important roots in the $20^{\text {th }}$ Century phenomenology movement associated with Husserl, Heidegger, Merleau-Ponty and others. It is in part because of these diverse influences that interpretations of social constructivism can diverge greatly [56]. It is proposed here that social constructivism and its parent, phenomenology, in tandem with the emergence of a new approach to philosophy of science embodied in the neuroscience of Maturana [57], Varela [37], Flores [38] and the organizational theorist Nonaka [58], point to an alternative approach to the problems that have otherwise befuddled Western philosophy. An important aspect of the approach in question is the acceptance of the relevance of key elements of Eastern thought, in tandem with the tenets and accomplishments of Western philosophy and science [37]. The epistemological framework of social constructivism is also embodied in the educational philosophy and practice of the renowned Brazilian educator Paolo Freire [59,60]. In the pages that follow, after some clarifications and considerations of hierarchies, we will explore some of the ramifications of a social constructivist orientation to health, medicine and healthcare, as well as some of the initiatives to date that have reflected such an approach.

\section{Evidence-Based Medicine (EBM): The Ultimate Confounder}

The evidence-based medicine (EBM) movement has insinuated itself as a protagonist and stakeholder in debates regarding the epistemology of science and its relationship to the practical use of clinical research in healthcare $[17,18]$. We define EBM as the educational movement to enhance the clinical research literacy of physicians, including physicians in training, introduced by the McMaster University based EBM Working Group in 1992 [11]. The label "evidence-based" had been introduced earlier by David Eddy in the context of a discussion of the use of research to inform clinical guideline efforts [61,62]. However, the EBM manifesto [11] was particularly effective in generating substantial attention and controversy [62]. This, together with EBM's emphasis on information from clinical trials and on hierarchies of clinical research evidence, not to mention the distinct inclination towards 'empire building' on the part of EBM founders that would become more evident over time [17], rapidly led to a tendency in the literature to equate the term 'evidence-based medicine' with the entire interface between clinical research and healthcare, including the clinical research enterprise itself [25,26,63].

Blurring the boundaries of the EBM initiative, as it was actually formulated, has served to obscure the epistemologically relevant features of the movement. What needs to be addressed in the context of this chapter is the role of EBM in corrupting the notion of a 'hierarchy of evidence'. To do this we need to recognize EBM as an expression of logical positivism within the arena of healthcare.

The EBM literature itself is sparse when it comes to explicit reference to philosophical currents. One of the few direct statements regarding epistemological orientation from EBM founders comes from Sackett, who identified the clinical epidemiology movement that led to EBM, as he conceived it, as 'nominalist' in orientation [64]. This assertion, which appeared prior to the public launch of the EBM movement, reinforces the characterization of EBM as an expression of logical positivism [39,56]. Many features of EBM demonstrate that logical positivism is the best fit as an underlying epistemological framework. Among these are the probabilistic emphasis on statistical data as an aid to diagnosis. EBM, as an educational initiative directed at clinical physicians, offered a set of evaluative and interpretive principles derived from the established literature on clinical research methodology [65]. The criteria, such as randomization, concealment of randomization and blinding, which were advanced as the basis for assessment of the quality of evidence supporting the validity of study results, were specific to particular clinical research designs. They had been developed from logical considerations pertaining to factors that could bias such results. As such, the process of their selection conforms to what has been characterized as the "logical" side of "logical positivism" [66]. More recently, investigators close to the EBM movement have taken great pains to subject these quality criteria themselves to empirical validation. An extensive body of research has involved comparison of the results of individual trials included within systematic reviews based on compliance or non-compliance with specific criteria. A preponderance of this research has suggested that such methodological characteristics, when present, are associated with smaller, and presumably more plausible, estimates of effect $[67,68]$.

We can recognize the research that targeted the criteria used within the instructional framework of EBM as the basis of evaluating the quality of clinical studies as fully consistent with the logical positivist framework [39,69]. In fact the entire framework advanced as the lexicon of EBM in the early 1990's [65,70,71] is consistent with this epistemological framework. Also compatible are the attempts to adjoin domains other than that of information from clinical research into the proposed EBM paradigm. As elaborated by Kolakowski [69], a central precept of logical positivism is that all sciences, including the social sciences, can and should be unified around a single set of specifications, specifications that are in turn compatible with those posited as essential to the advancement of knowledge within the natural sciences. This would seem to 
be the most satisfying interpretation from a philosophical standpoint of certain, otherwise bewildering, EBM founders' proposals, subsequent to the initial elaboration, to 'expand' the EBM perspective to encompass patient values and preferences and the elements of clinical expertise [72,73].

The proposed adjustments to the original EBM prescription were advanced without any substantive attempts to modify the original perspective on medical knowledge and teaching. The instructional frameworks informing workshops in EBM overseen by its original founders remained unchanged [25,74] and, notably, what is otherwise understood to constitute 'medical knowledge', that is, knowledge of the pathophysiological mechanisms of health and disease, was never added to the formulation. More recently, even more extravagant propositions aimed at advancing and expanding the EBM paradigm have suggested direct incorporation of patients' values, preferences and experiences, if not their actual personhood, into the EBM hierarchy of evidence $[16,75]$.

In certain circumstances, EBM founders and advocates do appear inclined to break out of the confines of a purely empiricist conceptual framework. We have elsewhere [76] described a process in which, at the point that such a framework comes up against irreconcilable contradictions in the course of pursuing a line of development, it transforms itself effectively into a rationalist construct as a means of getting beyond the constraints of the original epistemic stance. The relationship between EBM and the clinical guideline movement seems to reflect such a phenomenon [77], particularly when the specifics of the Grading Recommendations Assessment, Development and Evaluation (GRADE) developed by senior EBM founders are considered [78].

To illustrate the point in more detail, the notion advanced by EBM founders that information from clinical research, or 'evidence', speaks for itself with need only for a minimal degree of interpretation, although later abandoned by some EBM advocates [79], constituted an avowedly empiricist epistemic stance [8]. Further exemplifying the ultimate limitations of EBM as a paradigm for medical education and practice, after twenty years of development characterized by widespread successful incorporation of training in EBM skills into medical curricula at all levels of training, a multitude of studies of educational effectiveness failed to demonstrate any impact of EBM on physician behavior, clinical practice or patient outcomes [78,80,81]. In the interim, many of the original founders and developers of the EBM movement have turned their efforts to the development and implementation of clinical guidelines and related principles of implementation science and knowledge translation as means of closing the gaps between clinical research, health policy and clinical practice [78]. Clinical guidelines are complex instruments and the process of securing their uptake and adherence is more complex still. The overall process encompasses many dimensions and domains including the incorporation of the perspectives of sundry stakeholders to guideline use [82]. These domains of consideration are not easily reducible to the kinds of logical constructions that pass muster within a rigorously logical or probabilistic framework. Hence, the aforementioned shift in focus of activities, from the original EBM paradigm of change in clinical practice as an automatic consequence of education for research literacy, to the world of clinical guideline development and implementation, can be seen as an attempt to move away from rigid empiricism towards approaches more grounded in a real social context, shaped by human needs, goals and values.

\section{A Hierarchy of Hierarchies}

Having characterized the epistemic basis of the EBM movement, we are now ready to undertake consideration of the sometimes vexing matter of hierarchical schemes of research evidence, information and knowledge which EBM has played a prominent role in shaping and perhaps corrupting.

The issue of hierarchies has been a prominent one in discussions of healthcare, particularly hierarchies involving the place of research evidence within the policy and clinical decision-making process. Decision-makers are persons, and those persons include practitioners, whose ability to engage in decision-making relationships with service users as equals, employing empathy and respect, is a crucial feature of providing acceptable care - certainly of practicing in a way that can meaningfully be called 'person-centered'. It is a pivotal issue and one that may well define the epistemic viability of conceptual frameworks aimed at illuminating the possibility of a healthcare of the person, rather than of the 'patient' or of an impersonal population. Epistemic hierarchies that 'downgrade' features of professional awareness vital to best practice are, simply, inadequate characterizations of the relationship between knowledge and practice in healthcare - they are (as we will demonstrate) 'low-grade' hierarchies.

More generally, the process through which knowledge of ourselves and the universe develops can be seen as a matter of recognizing order, expressed in the language of structure and mechanism, and of identifying and creating relationships between those real, independent objects and our thoughts and concepts. The concept of hierarchy has traditionally played a key role in helping us 'structure' our understanding of the world and, not surprisingly, plays a key role in the development of science. Our purpose here is to explore the roles that hierarchical notions have played in the course of discussions bearing on the epistemology of a healthcare of the person.

As before, to explore the issue we need first to delineate what we are talking about sufficiently to avoid ambiguity of usage. The term 'hierarchy' may be appropriately applied to a variety of distinct contexts and relationships. For example, it may denote a simple ordering process, such as an organizational command structure. Although it constitutes important information for anyone who needs to navigate the organization from within or without, the arrangement is ultimately idiosyncratic. A 'hierarchy' may also refer to an ordering, or ranking, based upon an underlying quantitative principle such as years of education, the number of language fluencies etc. A still 
Figure 1 (A.) A 'designated' hierarchy such as a standard organizational chart. The ordering reflects criteria selected by the organizational leaders and is not objectively reproducible. (B.) An 'ordered' hierarchy in which the ranking of the elements is based upon well-defined properties of the elements. The ordering principle is externally defined and reproducible. (C.) A 'nested ' hierarchy in which successive levels subsume the properties of the preceding levels. The ordering reflects a developmental principle which may be externally defined or, in the case of an 'evolutionary hierarchy' intrinsically determined. The arrows indicate the directionality of hierarchical development. (Figure reproduced with permission from Dra. S. Silva)

A.

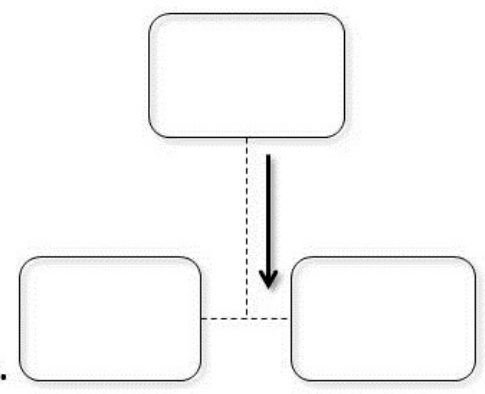

B.

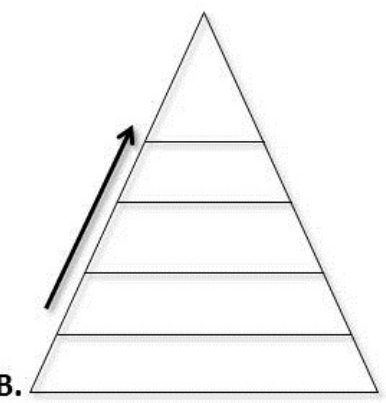

c.

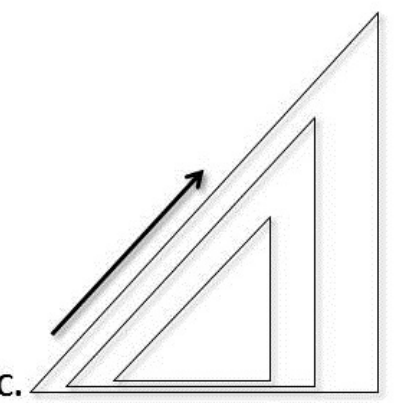

more complex notion can be conceptualized as a nested or 'evolutionary' hierarchy, in which each successive stage subsumes the entirety of the lower stages. For example, subatomic particles comprise the 'building blocks' that comprise inorganic matter which in turn comprises the basis of organic molecules leading to life forms, and then to creatures with advanced reasoning and creative abilities. Strictly, within the evolutionary paradigm, the governing principal of the hierarchy is the process through which successively higher levels are generated from the lower levels. However, in all cases of a 'nested' hierarchy, the emergent properties of the higher levels are not reducible to those of the lower, even though content within the lower levels is fully subsumed within that of the higher levels $[26,37,57]$.

To expand on this idea, these notions of hierarchy can be represented in terms of set theory (Figure 1). An example of a 'designated' hierarchy (A) is the array of individuals within an organizational map. In this case a simple set is comprised of all personnel within an organization who have designated leadership or executive roles combined with a designated ranking of authority. The chains of command and reporting may be intricate and will generally not conform to a simple ordering principle. Rather, multiple factors will contribute to the various choices and designations which may in fact be extraneous to individuals' experience or qualifications and may reflect entirely different criteria for different individuals. Importantly, knowledge of one such organizational scheme does not justify assumptions that might be made regarding the structure of a different organization.

A somewhat more advanced hierarchical framework (B) reflects the application of an external criterion to the members of the set. This is characteristically a quantitative attribute. The hierarchy of study designs introduced as part of the inaugural report of the Canadian Task Force on the Periodic Health Examination [83] constituted an attempt at the establishment of such a hierarchy. From the standpoint of a 'hierarchy of hierarchies' framework, a hierarchy based on application of a simple external criterion, consistently applied, generates a higher level of knowledge than does one based on simple designation. Flawed as it was, over the ensuing decades the Canadian Task Force scheme made it possible to know something about other 'evidence based' guidelines, particularly with respect to the kind of research that had been performed on specific questions across a broad range of clinical settings.

Figure 1C illustrates the nested hierarchy. Within it, each successive stage subsumes the contents of the previous one. In terms of conventional set theory notation, if $\mathrm{A}, \mathrm{B}, \mathrm{C}$ and $\mathrm{D}$ are successive stages in a hierarchical assent, then $\{(\mathrm{A} \subseteq \mathrm{B}) \subseteq \mathrm{C}\} \subseteq \mathrm{D}$, etc. The criteria by which the contents of the elements are determined are intrinsic, albeit a 'knower' is required to recognize and define the corresponding hierarchy, including the process through which each successive stage is generated from the earlier stages. Strictly, in an evolutionary hierarchy, such a knower is itself the product of self-organizing, emergent principal. In any case, a nested hierarchy uniquely conforms to knowledge of processes, as opposed to fixed or arbitrary ordering principles, and as a result it is aligned with the process through which knowledge itself emerges from the experience of self and of the world.

It is perhaps important to note that the validity and integrity of a hierarchy conforming to any of the described specifications should be considered to be attributable only to the consistency of application of those specifications. For example, the validity of an ordered hierarchy qua hierarchy depends only upon the intrinsic characteristics of the elements, not upon the validity of the premises underlying the externally imposed ordering principle.

Of the three types of hierarchy we have described, we are primarily concerned with the second and third which we can call the externally ordered and the nested 
hierarchies, respectively. Both bear an important relationship to the issues regarding person-centered healthcare that we are discussing. Much attention, and criticism, has been focused on the externally ordered, study design-based hierarchies of evidence that have appeared over the years since the Canadian Task Force published its first report on the periodic health examination [83]. These hierarchical concepts preceded the dawn of the EBM movement [78]. Despite their adoption, in various iterations, by that movement, they were neither introduced by nor properly define it. What the EBM movement did contribute was a constantly changing corruption of the integrity of hierarchical ordering from the standpoint of the concept of either an 'ordered' or an 'evolutionary' hierarchy conforming to either B or C in Figure 1.

Returning to the design-based, 'ordered' hierarchy of evidence as introduced in 1977 [83], this was based on a seemingly straightforward, if ultimately challengeable premise, namely that the method of allocation of human subjects within a comparative study framework is related to the likelihood of bias in the results, due to the varying ability to adequately control for confounding and modifying factors in the study population. It assumed that randomized allocation, which potentially is able to control for both known and unknown confounders, would be inherently superior to an observational design in which the researcher has no direct control over allocation. Similarly, an observational design based on a single, coherent, population, such as a prospective cohort study, was considered to encompass, more effectively, controls against confounding than one in which the subjects to be compared are drawn from different populations, such as in a casecontrol study. Historically, there proved to be some vindication for these over-simplified assumptions.

The era of randomized trials and the hierarchies of methodology based on them was ushered in, not as an ideological, or even an epidemiological movement, but rather as a pragmatic response to one of the most prominent pharmaceutical industry generated debacles in the post-World War II period, namely the thalidomide scandal [84]. Hundreds of dramatically deformed babies were born of mothers who had been urged to take the drug by their doctors at the behest of the marketing pressures exerted by the manufacturer. The scandal led to US congressional action spearheaded by then US senator Estes Kefauver, who drafted 1960's legislation which required trial evidence of both efficacy and safety as requirements for approval of new drugs by the Food and Drug Administration [25]. The requirement was for demonstration of efficacy and safety under research conditions; hence, the requirement for controlled trials and randomization. So, the driving impulse was political and pragmatic, more than it was ideological or epistemological. To be sure, clinical epidemiologists such as Archie Cochrane lent their support [12]. Furthermore, clinical guideline efforts soon adjusted to the ascendancy of the randomized trial in their approach to rating the quality of research evidence related to healthcare recommendations [83]. By the time EBM was launched in 1992, the dominance of the RCT over clinical research had been established for decades and in no way constituted its defining characteristic from an epistemological standpoint.
Although properly conforming to an ordered hierarchy, the design based framework for rating the quality of comparative clinical research studies was ultimately problematic. Many other factors to do with the design and conduct of such research are capable of undermining controls to prevent biased results and may invalidate the ranking of approaches to subject allocation and selection. The first attempts to revise and improve the hierarchy of evidence on the part of the educators and epidemiologists who served as the core of the EBM movement were aimed at incorporating aspects of the sample size, consistency of results across studies and perceived thresholds for assessment of clinical significance of the magnitude of effect into the design based scheme $[13,14]$. The results of these first forays into the arena of grading evidence for decisions and recommendations, although complex and unlikely to be adopted, were nonetheless confined to tangible aspects of clinical research and hence defensibly conformed to an ordered hierarchy within a well defined set. They were, however, soon to be superseded by a proposed scheme that could not be so defended [15].

In 2002, the inaugural compendium of the JAMA Users' Guides series, the flagship series of the EBM movement [65], proposed a hierarchy of evidence to be used in healthcare decision making that incorporated elements entirely foreign to intrinsic criteria for rating and ordering study quality [15]. Moreover, those elements corresponded to an entirely different construct, unique to the EBM movement, which had originally triggered the vehement opposition to the EBM educational initiative on the part of humanistically-oriented spokespersons that was voiced in major medical journals [85]. Specifically, the scheme included systematic reviews, randomized trials and observational studies positioned above information drawn from studies of physiological parameters in health and disease and also above clinical observations. The latter two elements, which can hardly be considered to be inherent to any clinical research design, invalidate the scheme from the standpoint of the definition of an externally ordered hierarchy, there being no definable category encompassing the elements of the set and no elaborated principle governing their order. Furthermore, these "foreign" elements reflect the invasion into an ostensibly design-based hierarchy on the part of a radically different construct, which had been interjected with the original announcement of the EBM initiative in 1992 [11]. The latter had proposed a restructuring of knowledge as it pertains to clinical practice and teaching, namely that the knowledge of the pathophysiology of health and disease and also knowledge born of clinical experience of individual practitioners, such as accumulated by healthcare professionals in the course of practice, be 'de-emphasized' relative to information drawn from clinical research. This restructuring is represented in Figure 2A. Subsequent publications by the EBM core group [15,17] have confirmed that the intended position for clinical knowledge and practitioner acumen within the proposed structure was at the very bottom of an ascending, three step hierarchy [86]. The ultimate incoherence of the resulting construct [86] and its incompatibility with the precepts of actual clinical practice $[85,87]$ have been abundantly elaborated in the literature. It will best serve our current purpose to 
Figure 2 Illustrating the erroneously ordered hierarchy of knowledge originally implied by the EBM literature (A) counterposed to corrected ranking (B). The latter conforms implicitly to a properly designated 'nested hierarchy' within which focused information from clinical research is filtered through the comprehensive array of medical scientific knowledge, including the knowledge of biochemistry, physiology, etc in health and disease and is ultimately integrated within the social and relational domain of contextualized knowledge from which healthcare decisions and choices are made. (Figure contributed by Dra. S. Silva)

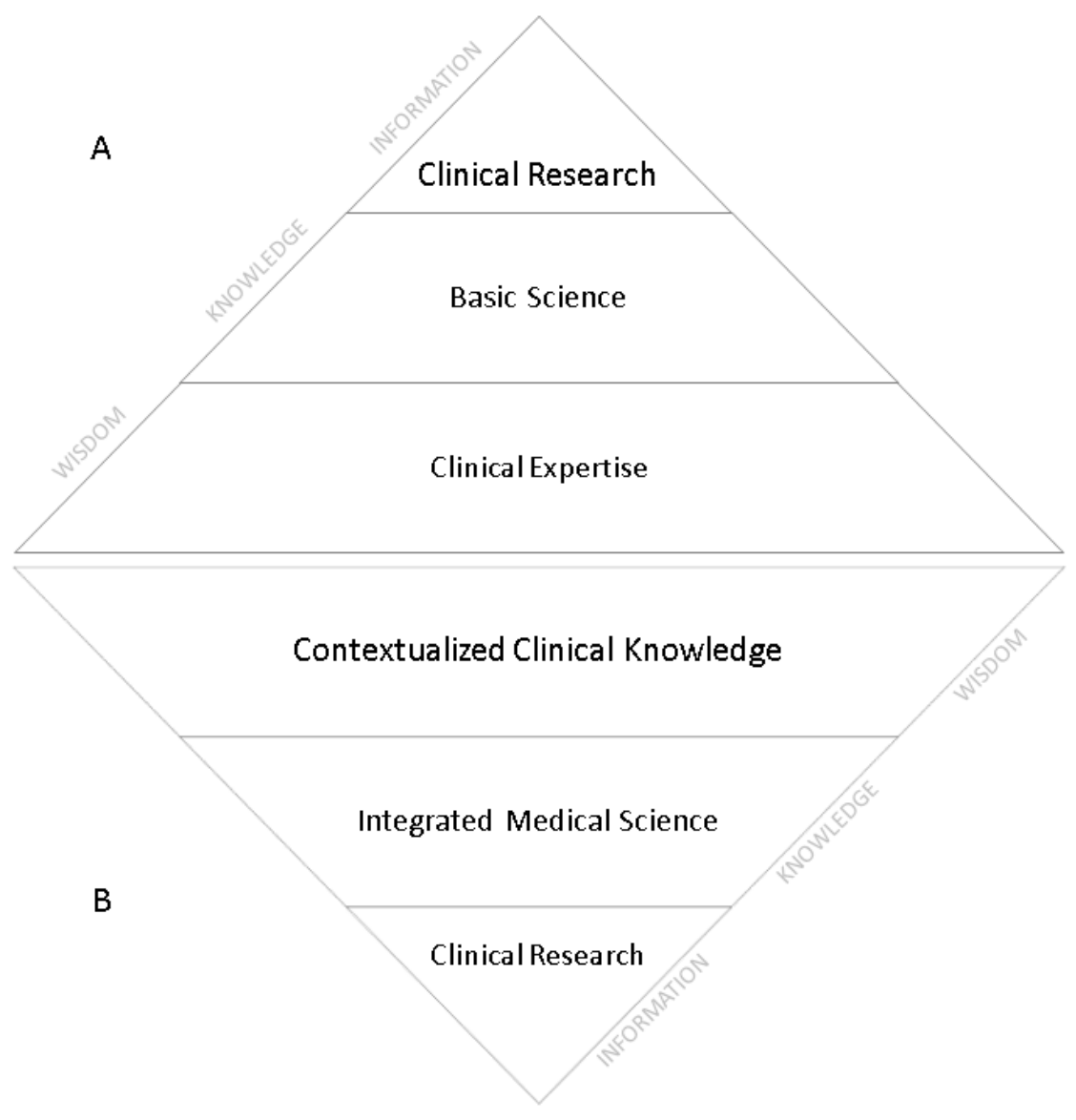

focus on the issue raised by the 'upside down' ordering [86] of the medical knowledge hierarchy posited by EBM in 1992.

The positioning of information from clinical research at the top of a hierarchy of knowledge, subordinating what is conventionally understood to constitute "medical knowledge”, that is, knowledge of human pathophysiology in health and disease, as well as other areas of basic medical science, and the working knowledge of experienced clinicians to successively lower levels, conforms strictly to a logical positivist philosophical stance. The "de-emphasis" of medical knowledge, as opposed to probabilistically framed information from clinical research, can be interpreted as a rejection of common sense realism, in the sense formulated by Bhaskar [88-90], and a countervailing embrace of nominalism, as acknowledged earlier by Sackett $[39,69]$. Furthermore, the relegation of clinical acumen to the lowest rung on the EBM ladder is highly suggestive of logical positivism's rejection of values, intuition, social interaction, empathy and tacit awareness as sources of knowledge [69].
Although EBM advocates later claimed to be regretful of their apparent dismissal of value laden considerations, particularly those of patients, as having bearing on healthcare decision-making [91,92], the persistent relegation of "expert experience" to the lowest rung of the EBM ladder within even the most recent iterations of the EBM credo [17] attests to the fact that, over the three decades since its first formulation, from an epistemological standpoint, little if anything has changed within the underlying EBM paradigm.

\section{The crucial, person-centered inversion}

If we turn the unhappy, 'upside down', hierarchical scheme posed by the EBM movement in 1992 right side up again, a remarkable transformation takes place; we are suddenly confronted by a plausible nested hierarchy conforming to the previously suggested specifications! Indeed, the lowest level of the three pronged scheme, the domain of clinical research, nourishes the realm of expanding medical 
knowledge and is subsumed within it. The second level is, in turn, subsumed within the highest level domain of relationally generated healthcare actions that draw upon the expertise, and shared medical knowledge, of the practitioner, the shared health and personal self-knowledge of patients and other recipients of healthcare (Figure 2B). The construct as a whole escapes not only the formal inconsistencies of the sundry but ill-formulated EBM 'hierarchies', but also the latter's highly constrained form of implied logical positivism and Popper's expanded 'falsificationist' form in addition [52]. The emergent, selforganizing properties of effective use of information and knowledge in healthcare, embodied in Montgomery's use of the Aristotelian term "phronesis" (practical wisdom) [53], then come to the fore. The wise practitioner of course uses information from clinical research. The higher levels within this hierarchy in no sense invalidate or replace the lower, any more than a complex organism ceases to be made of atoms, or a reasoning person ceases to be an organism. Rather, the person-centered practitioner wisely applies information from clinical research and medical knowledge to the specific and potentially unique case which the individual person/s in front of her present. This ability entails a level of professional and personal development which requires, in addition to a proper understanding of the relevant clinical research, the human and social skills that allow a practitioner to identify with the needs and values of others - skills which defenders of person-centered care have noted are missing from the stripped-down, 'biomedical reductionist' [93,94] model of clinical decision-making. More concisely, such an approach requires a practitioner to activate and commit her own personhood to the interaction.

\section{Practical Applications}

If we have, hopefully, adequately illustrated the concept of a 'hierarchy of hierarchies' as it relates to issues surrounding the integration of research with the social and relational processes of healthcare, we still need to establish the usefulness and necessity of such a construct. One approach to this task would be simply to posit a world of healthcare in the absence of externally ordered and nested hierarchies of information and knowledge and to then imagine what it would look like. Cases in which conventional hierarchical controls on research quality, such as those commonly used by developers of clinical guidelines, have broken down may be instructive here. We may cite as examples the re-emergence of childhood infectious diseases in the wake of laxity in adoption of standard immunizations and the epidemic of deaths stemming from misuse of prescription opioid drugs.

In the first example, a loosely designed, uncontrolled study reported an apparent association between childhood immunizations and autism [95]. The weaknesses of the study were quickly identified and it was ultimately assessed to have been based upon fabricated data [96]. The original report was retracted by the journal that had published it. Despite this, the publication that had created the controversy was widely disseminated and frequently cited in the peer reviewed literature as well as in the lay press and social media. It ultimately became the rallying cry for an expanding mistrust of immunizations within the lay public and consumer advocacy groups internationally. It is thought that the Wakefield study has been responsible for declining childhood immunization rates. Outbreaks of measles and polio with accompanying fatalities, polio having been once thought to be near eradication as a result of the vaccine, are being reported on several continents [97-99].

The second example traces to an errant 1980 report which was published as a letter to the New England Journal of Medicine [100]. The one hundred word Letter to the Editor by-passed the normal peer review process. It was based on an unstructured retrospective review of poorly identified medical records of patients admitted to hospital over an undisclosed time period and it concluded that "addiction is rare" among hospitalized patients receiving opiates [100]. The letter was seized upon by vested interests within the pharmaceutical industry as proof that opioid medications could be safely prescribed to any and all patients with painful conditions irrespective of etiology [101]. It is estimated that 200,000 adults in the US alone died of narcotic overdoses between 1999 and 2016 [102].

The above two examples demonstrate that even oversimplified, flawed, design-based criteria for assessment of research quality may serve to protect the public from relatively disastrous consequences that may ensue when individuals and corporations with vested self-interests and ample resources are given a free hand in the conduct and dissemination of clinical research. As previously noted, the privileged position of randomized trials atop the traditional design based hierarchy dates from regulatory and legislative interventions in the late 1960's that resulted from the thalidomide debacle [25,84]. Hence, the advent of the ordered hierarchy of designs dominated by randomized trial evidence was adaptive from the perspective of societal and ultimately individual patient needs. The rationale for even an imperfect and epistemologically flawed 'hierarchy of research evidence' is not merely an abstract philosophical issue of interest within academic circles, but is rather one of social responsibility, and one that carries important consequences to individuals, their families and Society.

Turning to positive arguments for the necessity of properly framed evolutionary hierarchies, perhaps the most eloquent have been advanced by Michael Polanyi [103,104]. In a 1968 article published in Science [104] that author constructed an elegant demonstration of why life forms, machines and human consciousness cannot be derived from the linear laws of chemistry and physics, even though the latter are necessarily obeyed at every level. As one moves from inorganic matter to the emergence of life forms, the latter are made up of the materials and building blocks that comprise the former. Laws of entropy, conservation of momentum etc., are obeyed within the higher sphere; however, the life forms themselves cannot be derived from those laws. Polanyi traces the process of emergence through the universe of animals, within which tools are developed, identified and used. Only humanity, however, creates machines. Tools are 
essential to the building of machines but, again, one cannot derive the machines themselves from the tools that are used to make them, nor from the laws of chemistry and physics that prevail across the whole process. In this way, it is demonstrated that one cannot comprehend the universe that contains all of these levels without recognizing the principle of an evolutionary hierarchy and the processes of emergence and self-organization that lead to and stem from it.

Polanyi’s 1968 demonstration was directed to clarifying the necessary relationship between the coding structure of DNA, which had been discovered by Watson and Crick only a little more than a decade earlier [105] and the developmental processes that generate an individual organism, voice, words, grammatical syntax, language, and ultimately human consciousness. An analogous escalating hierarchical relationship can be demonstrated with respect to data, information, knowledge, and knowledge for action, or phronesis [106]. Recognition of such a nested hierarchy is ultimately itself an epistemologically sensitive issue. Specifically, it requires recognition of the crucial distinction between information and knowledge. Such a distinction is ultimately excluded within, for example, Popper's scheme. For Popper, knowledge is that which is contained in books and the domain of 'pure knowledge' is ultimately a repository of information from various sources that is potentially on tap for instrumental use [52]. The EBM movement, similarly, denies a qualitative distinction between information, such as that which is generated by clinical research, and knowledge [86]. This is perhaps clearest insofar as, under the EBM paradigm [11], the information from clinical research is proposed to be of a higher order than what is otherwise commonly understood to constitute medical knowledge.

Inquiries into the cognitive processes involved in everyday clinical and diagnostic reasoning provide an interesting domain of application of the above principle. Henry [1] highlights the importance of Polanyi's concept of tacit knowing [103] to the role of pathophysiological knowledge and understanding in clinical practice. Supporting his suggestion, investigations of diagnostic reasoning in both experts and novices demonstrate that at least two phases of cognition are at play, namely a 'forward' and a 'backward' reasoning process [107,108]. The former involves a process that resembles inductive reasoning and draws heavily upon background pathophysiological knowledge in a quasi-intuitive, nonanalytical fashion. The latter involves deliberative processing of specific pieces of information, such as elements of history and physical findings drawn from an individual patient, for purposes of verifying or falsifying hypotheses derived from the inductive process. It corresponds to an analytical, hypothetical-deductive, process. The balance between these two aspects of diagnostic reasoning may differ between novices and experts $[107,108]$. The latter appear to rely more on the non-analytical 'forward reasoning' process. Most useful for purposes of our discussion is the recognition that these, and perhaps other, cognitive dimensions are present whenever a clinical encounter takes place and that the process as a whole exemplifies the way that specific information, be it from a patient or from clinical research, interacts with and informs a growing wellspring of underlying knowledge.

Provided we have an epistemologically competent understanding of the nature of knowledge, a nested hierarchy fulfilling the previously proposed specifications is defined through the escalation from data (defined as that which is transmissible via various electronic channels such as computers), through information (which may be simple factual or more complex but which requires some interpretive inputs on the part of a user), to knowledge (requiring integration with other domains of discipline and experience) and, finally, to the realm of judicious and concerted action, or wisdom.

The foregoing example is, for simplicity, confined to the domain of a single mind, that of the practitioner. To more fully recognize the qualitative, hierarchical, distinction between information and knowledge, it is necessary to escape the constraints of the traditional opposition of subject and object, the knower and thing known. The ineliminable qualititative component of hierarchy can only proceed from the judging, evaluating, knowing subject, and this subject's information-organising activity must now be recognized as having a proper role in the development and application of medical science [109]. A realist interpretation of social constructivism constitutes one such avenue of escape; the Chilean school of evolutionary neuroscience [57], which could also be considered philosophically to be a stream or variant within social constructivism, constitutes another. It would be difficult to imagine a more eloquent formulation of the social constructivist concept of knowledge than that penned by the renowned Brazilian educator and education theorist, Paulo Freire:

\footnotetext{
"Knowledge does not extend from those who consider they know to those who consider they do not know. Knowledge is built in the relationship between human beings and perfects itself in the Critical Problematization of these relations" [60].
}

The epistemology of a healthcare of the person, as opposed to simply informed treatment of patients on the part of well meaning but ultimately paternalistic practitioners, requires a vision of knowledge that transcends the simple storage and imparting of information. Realization of such a vision completes a necessary evolutionary hierarchy of knowledge and wisdom.

\section{Concluding Comments}

The phrase "patient-centered medicine" was first coined by the Balints, Michael and Enid, in the context of having conducted a unique seminar for primary care practitioners in London during the 1950's [110,111]. Their approach drew on principles of psychoanalysis applied to general health issues and emphasized the importance of relational principles across the full spectrum of protagonists in the 
primary care setting [111]. It also opened the door to active consideration of the asymmetric unity of subject and object, of knower and known, and, implicitly, the personhood of both patient and practitioner within a productive clinical relationship. The Balints, however, stopped short of attempting to elaborate their vision in a fashion that identified salient issues of epistemology. Over the ensuing six decades, as the concept of patient-centered healthcare was explored and developed at the University of Rochester in the US and elsewhere [112], and as multiple independent initiatives described alternatives to the paternalistic medical model that had dominated healthcare since the days of Hippocrates, attention to the relevant epistemology of healthcare relationships and actions continued to be rare. Ultimately, Balints' phrase 'patientcentered care' went the way of all buzzwords [22], taking on a multiplicity of meanings that would have certainly been unrecognizable to its initiators [24].

The Relationship Centered Care (RCC) initiative sponsored by the Pew and Fetzer Foundations in the early 1990's [48,113] marked an important milestone in the productive linkage of healthcare constructs and the domains of philosophy and epistemology. It also embodied a return to the relational principles embedded in the Balints' formulations and reports. Specifically, the RCC authors related the phenomenology of Merleau-Ponty and the concepts introduced by Polanyi to the recognition of the primacy of relational principles in defining the processes of healthcare and clinical practice. As with the Balints, in RCC both practitioner and patient share the affective, and not only the factual and 'professional' dimensions of the interactions. It is this that defines the personhood of all parties and protagonists and that creates the social context within which knowledge, understanding, decisions and actions can be mutually satisfying. Within that framework, the RCC authors recognized the importance of integration of information from clinical research into the social processes of healthcare at the same time that they established the necessary dominion of those processes over research and the mere exchange of information [113].

More recently still, the elaboration of the "mindlines" construct by Gabbay and Le May [113] also identified with philosophical currents within the social constructivist stream. Gabbay and Le May conducted ethnographic studies within several clinics within the UK that had been independently recognized as outstanding from a quality of care standpoint. Specifically, they observed the use of information from clinical research and guidelines within the multidisciplinary social processes of the clinics in question. They found that the practitioners were conversant with the latest studies and recommendations but not in a fashion that conforms to the practice models proposed by EBM founders [114]. That is, they did not take time out from practice to access research reports or guidelines, even though ready availability of computerized electronic resources would have allowed them to do so. Rather, practitioners' reference to and use of such information was at all points integrated into the social interactions of the clinic staff, which included meetings in which specific cases and clinical issues were discussed. Hence, within the high quality real world clinical settings observed by
Gabbay and Le May, information generated by research and recommendations thereof served to inform and enhance clinical practice through integration into social processes, but never took center stage over the form and content of those processes. Subsequent work of the authors has taken the form of development of approaches based upon their proposed 'mindlines' construct and has involved fostering evidence enriched communities of practice and learning communities within established healthcare environments $[115,116]$.

Several points of coherence between the above cited frameworks and the epistemological issues discussed in this chapter are worthy of emphasis. Firstly, in both cases, social processes and relational principles supersede the 'objective' interpretation of information from clinical research in driving the processes of clinical care. Secondly, both the RCC initiative and the investigational perspectives of Gabbay and Le May seek to integrate enhanced attention to the results of clinical research as essential features of efforts to improve the quality of healthcare. The principles inherent in the properly defined evolutionary hierarchy of information, knowledge and action, or 'wisdom', are prominently displayed in these two approaches.

Earlier in this chapter we made note of the persistent and unsatisfying gap between the domain of clinical research and that of clinical practice that characterizes the world of healthcare. An important feature of this disconnect is the unidirectional nature of most attempts to close the gap in question. Drawing on a concept originally developed within the world of business and marketing [117], they reflect a "push" orientation. Research designed and conducted within an environment foreign to that of clinical practice or policy development is 'pushed' upon leaders and practitioners within the latter contexts. This is a losing strategy within healthcare, dominated by individuals such as physicians, who have been trained to make life and death decisions on behalf of patients, for whose wellbeing they are uniquely responsible and who necessarily believe first and foremost in their own adequate competency in doing so. Inhabitants of the world of healthcare policy and practice perceive that of research to constitute an 'ivory tower', divorced from the real life world that they inhabit and unlikely to have trustworthy products or advice to offer it.

A possible alternative, the so-called 'pull' approach, was suggested in the course of a lecture delivered in 2009 by Professor Kenneth Prewitt of the Columbia University School of International and Public Affairs [118] and was echoed in the previously cited report of the US National Research Council which Professor Prewitt chaired [27]. Prewitt suggests that, instead of researchers conceptualizing and generating their products within the insulated environments of academia, or the profit oriented environment of private industry, they interact with and ultimately defer to the communities within which those products are proposed to be used and generate their research ideas and approaches in the context of those interactions. Such an approach is consistent with the 'communities of practice' framework described by Gabbay and Le May [114]. It would seem that equality of personhood within the clinical relationships, coexisting 
with the inherently asymmetrical element dictated by the professional training, expertise and responsibilities of the practitioner, mandates that the relationship and communications go beyond the confines of a mere exchange of information [37]. On a level that transcends the quality of relevant research, the 'relational validity' of the resulting context needs to be maximized.

Engagement of stakeholders, including patients and healthcare consumers, in efforts such as the development of clinical guidelines, constitutes another relationallybased approach to closing the gap. To be effective, such efforts need to be approached in such a way that the stakeholders neither feel 'left out' amidst an epidemiologically driven 'boys club', nor under pressure to turn themselves into 'grass roots epidemiologists' [119]. Irrespective of issues of relative effectiveness of different relationally based approaches, it seems unlikely that the gap between clinical research and healthcare practice will do anything but continue to widen unless and until relevant efforts reflect a viable epistemological foundation.

\section{Acknowledgements and Conflicts of Interest}

The authors wish to acknowledge Dr. Jeremy Simon MD PhD of the Department of Emergency Medicine, Columbia University, NYC and Dra. Suzana Alves Silva MD PhD, Head, Epidemiology Department HCor, Managing Partner of Instituto Alicerce, São Paulo, Brazil for helpful reading and commenting on the manuscript in various stages of development and Dra. Silva for designing the figures included in this chapter.

This paper reproduces Chapter 19 [a] of a forthcoming volume which is being serialised in the Journal in advance of the publication of the book itself in late 2020. For details see [b]. [a] Wyer, P \& Loughlin, M. (2020). Person Centred Healthcare and Clinical Research: the necessity of an evolutionary hierarchy of knowing and doing. In: Person Centered Care: Advanced Philosophical Perspectives. Loughlin, M. \& Miles, A. (Eds.), pp. 265287. London: Aesculapius Medical Press. [b] Asbridge, J.E. (2020). Progress in the conceptual understanding of person-centered health and social care. "Person Centered Care: Advanced Philosophical Perspectives”. Loughlin, M. \& Miles, A. (Eds.). London. Aesculapius Medical Press. European Journal for Person Centered Healthcare 8 (1) 17-19. The authors report no conflicts of interest.

\section{References}

[1] Henry, S.G. (2010). Polanyi's tacit knowing and the relevance of epistemology to clinical medicine. Journal of Evaluation in Clinical Practice 16 (2) 292-297.

[2] Entwistle, V.A. \& Watt, I.S. (2013). Treating Patients as Persons: A Capabilities Approach to Support Delivery of
Person-Centered Care. American Journal of Bioethics 13 (8) 29-39.

[3] Goodrich, J. \& Cornwell, J. (2008). Seeing the person in the patient. London, UK: King's Fund.

[4] Fulford, K.W.M. (2020). Groundwork for a metaphysic of person-centred care: a contribution from Ordinary Language Philosophy. In: Person Centred Care: Advanced Philosophical Perspectives. Loughlin, M. \& Miles, A. (Eds.), pp. 57-72. London: Aesculapius Medical Press.

[5] Buetow, S. (2016). Person-centred Health Care. Balancing the Welfare of Clinicians and Patients. London: Routledge.

[6] Brown, J. (2020). Psychiatry, power and the person. In: Person Centred Care: Advanced Philosophical

Perspectives. Loughlin, M. \& Miles, A. (Eds.), pp. 361-

378. London: Aesculapius Medical Press.

[7] Loughlin, M. (2008). Reason, reality and objectivity: shared dogmas in the way both scientistic and postmodern commentators frame the EBM debate. Journal of Evaluation in Clinical Practice 14 (5) 665-671.

[8] Loughlin, M. (2009). The basis of medical knowledge: judgement, objectivity and the history of ideas. Journal of Evaluation in Clinical Practice 15 (6) 935-940.

[9] Loughlin, M., Lewith, G. \& Falkenberg, T. (2013). Science, practice and mythology: a definition and examination of the implications of scientism in medicine. Health Care Analysis 21 (2) 130-145.

[10] Miles, A. \& Asbridge, J.E. (2014). The European Society for Person Centered Healthcare (ESPCH) - raising the bar of health care quality in the Century of the Patient. Journal of Evaluation in Clinical Practice 20, 729-733.

[11] Evidence-Based Medicine Working Group. (1992). Evidence-based medicine: A new approach to teaching the practice of medicine. Journal of the American Medical Association 268, 2420-2425

[12] Cochrane, A.L. (1972). Effectiveness \& Efficiency: Random Reflections on Health Services. London: The Royal Society of Medicine Press.

[13] Guyatt, G.H., Sackett, D.L., Sinclair, J.C., Hayward, R., Cook, D.J. \& Cook, R.J. (1995) Users' Guides to the Medical Literature. IX. A Method for Grading Health Care Recommendations. Evidence-Based MedicineWorking Group. Journal of the American Medical Association 274 (22) 1800-1804.

[14] Wilson, M.C., Hayward, R.S., Tunis, S.R., Bass, E.B. \& Guyatt, G. (1995). Users' guides to the Medical Literature. VIII. How to use clinical practice guidelines. B. what are the recommendations and will they help you in caring for your patients? The Evidence-Based Medicine Working Group. Journal of the American Medical Association 274 (20) 1630-1632.

[15] Guyatt, G., Haynes, B., Jaeschke, R., et al. (2002). Introduction: The Philosophy of Evidence-Based Medicine. In: User's Guides to the Medical Literature: A Manual for Evidence-based Clinical Practice. G. Guyatt \& D. Rennie (Eds.), pp. 3-12. Chicago: AMA Press.

[16] Greenhalgh, T., Howick, J., Maskrey, N. \& Evidence Based Medicine Renaissance Group. (2014). Evidence based medicine: a movement in crisis? British Medical Journal 348 (g3725). 
[17] Djulbegovic, B. \& Guyatt, G.H. (2017). Progress in evidence-based medicine: a quarter century on. Lancet 390, 415-423.

[18] Djulbegovic, B., Guyatt, G.H. \& Ashcroft, R.E. (2009). Epistemologic Inquiries in Evidence-Based Medicine. Cancer Control 16,158-168.

[19] Berwick, D.M. (2016). Era 3 for Medicine and Health Care. Journal of the American Medical Association 315, 1329-1330.

[20] Berwick, D.M. (2017) Comments to E-GAPPS III Conference, New York Academy of Medicine, March 21, 2017, in New York City.

[21] Loughlin, M. (2002). Ethics, management and mythology. Oxford: Radcliffe Medical Press.

[22] Loughlin, M. (2002). On the buzzword approach to policy formation. Journal of Evaluation in Clinical Practice 8, 229-242.

[23] Loughlin, M. (2014). What Person-Centered Medicine is and isn't: Temptations for the 'soul' of PCM. European Journal for Person Centered Healthcare 2 (1) 16-21.

[24] Tanenbaum, S.J. (2015) What Is Patient-Centered Care?: A Typology of Models and Missions. Health Care Analysis 23 (3) 272-287.

[25] Wyer, P. \& da Silva, S.A. (2015). 'One mission accomplished, more important ones remain': commentary on Every-Palmer, S. \& Howick, J. (2014). How evidencebased medicine is failing due to biased trials and selective publication. Journal of Evaluation in Clinical Practice 20 (6) 908-914. Journal of Evaluation in Clinical Practice 21 (3) 518-528.

[26] Wyer, P. \& Silva, S.A. (2015). 'All the King's horses . . .' the problematical fate of born-again evidence-based medicine: commentary on Greenhalgh, T., Snow, R., Ryan, S., Rees, S. \& Salisbury, H. (2015). Six 'biases' against patients and carers in evidence-based medicine. BioMed Central Medicine 13, 200. Journal of Evaluation in Clinical Practice 21 (6) E1-E10.

[27] Prewitt, K., Schwandt, T. A. \& Straf, M.L. (2012). Using Science as Evidence in Public Policy. Washington DC: National Research Council.

[28] Barnett, M.L. \& Linder, J.A. (2014). Antibiotic prescribing for adults with acute bronchitis in the United States, 1996-2010. Journal of the American Medical Association 311 (19) 2020-2022.

[29] Cabana, M.D., Rand, C.S., Powe, N.R., Wu, A.W., Wilson, M.H., Abboud, P.C., Rubin, H.R. (1999). Why don't physicians follow clinical practice guidelines? A framework for improvement. Journal of the American Medical Association 282 1458-1465.

[30] Callender, T., Woodward, M., Roth, G. et al. (2014). Heart Failure Care in Low- and Middle-Income Countries: A Systematic Review and Meta-Analysis. PLoS Medicine 11 (8) e1001699.

[31] McGlynn, E. A., Asch, S.M., Adams, J., Keesey, J., Hicks, J., DeCristofaro, A. \& Kerr, E.A. (2003). The quality of health care delivered to adults in the United States. New England Journal of Medicine 348, 2635-2645. [32] Worrall, G., Chaulk, P. \& Freake, D. (1997). The effects of clinical practice guidelines on patient outcomes in primary care: a systematic review. Canadian Medical Association Journal 156 (12) 1705-1712.
[33] Straus, S., Tetroe, J. \& Graham, I.D. (2013). Knowledge Translation in Health Care, 2nd Edition. Oxford: Wiley-Blackwell.

[34] Elwyn, G., Rix, A., Holt, T. \& Jones, D. (2012). Why do clinicians not refer patients to online decision support tools? Interviews with front line clinics in the NHS. BMJ Open 2, e001530.

[35] Stacey, D., Légaré, F., Lewis, K. et al. (2017). Decision aids for people facing health treatment or screening decisions. Cochrane Database of Systematic Reviews 4:CD001431.

[36] Nonaka, I. (1994). A dynamic theory of organizational knowledge creation. Organization Science 5, 14-37.

[37] Varela, F.J., Thompson, E. \& Rosch, E. (1991). The Embodied Mind. Cambridge, MA: MIT.

[38] Winograd, T. \& Flores, F. (1986). Understanding Computers and Cognition: A New Foundation for Design. Indianapolis: Addison-Wesley.

[39] Hjorland, B. (2005). Empiricism, rationalism and positivism in library and information science. Journal of Documentation 61, 130-155.

[40] Newton, W. (2001). Rationalism and Empiricism in Modern Medicine. Law and Contemporary Problems 64, 299-316.

[41] Plato. (1983). The Republic. Harmondsworth: Penguin Books.

[42] Aristotle. (2012). Rhetoric. London: Harper Collins.

[43] Anscombe, E. \& Geach, P.T. (1954). Descartes' philosophical writings. London: Thomas Nelson and Sons. [44] Locke, J. (1983). An Essay Concerning Human Understanding. London: Everyman Library.

[45] Hume, D. (1989). A treatise of human nature. Oxford: Clarendon Press.

[46] Engel, G.L. (1977). The Need for a New Medical Model: A Challenge for Biomedicine. Science 196, 129136.

[47] Malterud, K. (1995). The legitimacy of clinical knowledge: Towards a medical epistemology embracing the art of medicine. Theoretical Medicine and Bioethics 16 (2)183-198.

[48] Tresolini, C. \& Pew-Fetzer Task Force. (1994). Health Professions Education and Relationship-Centered Care. In: Pew Health Professions Commission. Available at: https://www.pewresearch.org/.

[49] Berkeley, G. (1972). A New Theory of Vision and other writings. London: JM Dent \& Sons Ltd.

[50] Chomsky, N. (1967). A Review of B. F. Skinner's Verbal Behavior. In: Readings in the Psychology of Language. L.A. Jakobovits \& M.S. Miron. (Eds.), pp. 142143. Upper Saddle River, NJ: Prentice-Hall.

[51] Nagel, T. (1986). The view from nowhere. Oxford: Oxford University Press.

[52] Popper, K. (1989). Objective knowledge: An evolutionary approach. Oxford: Clarendon Press.

[53] Montgomery, K. (2006). How Doctors Think: Clinical Judgment and the Practice of Medicine. Oxford: Oxford University Press.

[54] Mayes, C., Williams, J., Kerridge, I. \& Lipworth, W. (2018). Scientism, conflicts of interest, and the marginalization of ethics in medical education. Journal of Evaluation in Clinical Practice 24 (5) 939-944. 
[55] Simon, J.R. (2008). Constructive Realism and Medicine an approach to medical ontology. Perspectives in Biology and Medicine 51, 353-366.

[56] Simon, J.R. (2011). Medical Ontology. In: Handbook of the Philosophy of Science, Volume 16: Philosophy of Medicine. F. Gifford. (Ed.). Oxford: Elsevier.

[57] Maturana, H.R. \& Varela, F.J. (1987). The Tree of Knowledge. Boston: Shambhala.

[58] Nonaka, I. \& Takeuchi, H. (1995). The KnowledgeCreating Company. New York: Oxford University Press.

[59] Freire, P. (1970). Pedagogy of the Oppressed. New York: Herder and Herder.

[60] Freire, P. (1974). Education for Critical Consciousness. New York: Continuum.

[61] Eddy, D.M. (1990). Practice Policies: Where Do They Come From? Journal of the American Medical Association 263, 1265-1275.

[62] Eddy, D.M. (2005). Evidence-based medicine: A unified approach. Health Affairs 24, 9-17.

[63] Wyer, P.C. \& Silva, S.A. (2013). Tarnished Gold: The Sickness of Evidence-based Medicine by Steve Hickey and Hilary Roberts: EBM as an Avatar of Modern Medicine. European Journal for Person Centered Healthcare 1, 8087.

[64] Sackett, D.L., Haynes, R.B., Guyatt, G.H. \& Tugwell, P. (1991). Preface. In: Clinical Epidemiology A Basic Science for Clinical Medicine. D.L. Sackett, R.B. Haynes, G.H. Guyatt \& P. Tugwell. (Eds.), pp. ix-xv. Boston: Little Brown \& Co.

[65] Guyatt, G.H. \& Rennie, D. (1993). Users' guides to the medical literature. Journal of the American Medical Association 270 (17) 2096-2097.

[66] Smith, L.D. (1986). Behaviorism and Logical Positivism: A Reassessment of the Alliance, Chapter Two, "The Logical Positivist View of Science", pp. 26-65. Stanford, CA: Stanford Uiversity Press.

[67] Berkman, N.D., Santaguida, P.L., Viswanathan, M. \& Morton, S.C. (2014). The Empirical Evidence of Bias in Trials Measuring Treatment Differences. Methods Research Report. In: AHRQ Publication No. 14-EHC050EF. Rockville, MD: Agency for Healthcare Research and Quality.

[68] Page, M.J., Higgins, J.P.T., Clayton, G., Sterne, J.A.C., Hróbjartsson, A. \& Savović, J. (2016). Empirical Evidence of Study Design Biases in Randomized Trials: Systematic Review of Meta-Epidemiological Studies. PLoS One 11 (7) e0159267.

[69] Kolakowski, L. (1968). The Alienation of Reason: A History of Positivist Thought. New York: Doubleday \& Co.

[70] Guyatt, G.H., Sackett, D.L. \& Cook, D.J. (1993). Users' guides to the medical literature. II. How to use an article about therapy or prevention. A. Are the results of the study valid? Evidence-Based Medicine Working Group. Journal of the American Medical Association 270 (21) 2598-2601.

[71] Guyatt, G.H., Sackett, D.L. \& Cook, D.J. (1994). Users' guides to the medical literature. II. How to use an article about therapy or prevention. B. What were the results and will they help me in caring for my patients?
Evidence-Based Medicine Working Group. Journal of the American Medical Association 271 (1) 59-63.

[72] Haynes, R.B., Devereaux, P.J. \& Guyatt, G.H. (2002). Clinical expertise in the era of evidence-based medicine and patient choice. ACP Journal Club 136, A11-A14.

[73] Haynes, R.B., Sackett, D.L., Gray, J.R., Cook, D.C. \& Guyatt, G.H. (1996). Transferring evidence from research into practice: 1 . The role of clinical care research evidence in clinical decisions [Editorial]. ACP Journal Club 125, A14-A16.

[74] Murad, M.H., Montori, V.M., Kunz, R., Letelier, L.M., Keitz, S.A., Dans, A.L., Silva, S.A. \& Guyatt, G.H. (2009). How to teach evidence-based medicine to teachers: reflections from a workshop experience. Journal of Evaluation in Clinical Practice 15, 1205-1207.

[75] Greenhalgh, T., Snow, R., Ryan, S., Rees, S. \& Salisbury, H. (2015). Six 'biases' against patients and carers in evidence-based medicine. BioMed Central Medicine 13 (1) 200.

[76] Loughlin, M., Wyer, P. \& Tanenbaum, S.J. (2016). Teaching by (bad) example: what a confused attempt to “advance” EBM reveals about its underlying problems: Commentary on Jenicek, M. (2015). Do we need another discipline in medicine? From epidemiology and evidencebased medicine to cognitive medicine and medical thinking. Journal of Evaluation in Clinical Practice 21, 1028-1034. Journal of Evaluation in Clinical Practice 22, 628-633.

[77] Kelly, M.P. (2018). The need for a rationalist turn in evidence-based medicine. Journal of Evaluation in Clinical Practice 24 (5) 1158-1165.

[78] Wyer, P.C. (2018). From MARS to MAGIC: The remarkable journey through time and space of the Grading of Recommendations Assessment, Development and Evaluation initiative. Journal of Evaluation in Clinical Practice 24 (5) 1191-1202.

[79] Haynes, R.B., Devereaux, P.J. \& Guyatt, G.H. (2002). Physicians' and patients' choices in evidence based practice: Evidence does not make decisions, people do. British Medical Journal 324 (7350) 1350.

[80] Ahmadi, S., Baradaran, H.R. \& Ahmadi, E. (2015). Effectiveness of teaching evidence-based medicine to undergraduate medical students: A BEME systematic review. Medical Teacher 37, 21-30.

[81] Coomarasamy, A. \& Khan, K.S. (2004). What is the evidence that postgraduate teaching in evidence based medicine changes anything? A systematic review. British Medical Journal 329, 1017-1021.

[82] Institute of Medicine. (2011). Clinical Practice Guidelines We Can Trust. Washington, DC: National Academies Press.

[83] Canadian Task Force on the Periodic Health Examination. (1979). The periodic health examination. Canadian Medical Association Journal 121, 1193-1254.

[84] Glauberman, S. (1997). The Real Thalidomide Baby: The Evolution of the FDA in the Shadow of Thalidomide, 1960-1997. Available https://dash.harvard.edu/handle/1/8852132.

[85] Tanenbaum, S.J. (1993). What Physicians Know. New England Journal of Medicine 329, 1268-1271. 
[86] Silva, S.A. \& Wyer, P.C. (2009). Where is the wisdom? II - Evidence-based medicine and the epistemological crisis in clinical medicine. Exposition and commentary on Djulbegovic, B., Guyatt, G.H. \& Ashcroft, R.E. (2009). Cancer Control 16, 158-168. Journal of Evaluation in Clinical Practice 15, 899-906.

[87] Tanenbaum, S.J. (1994). Knowing and Acting in Medical Practice:The Epistemological Politics of Outcomes Research. Journal of Health Politics, Policy and Law 19, 27-44.

[88] Bhaskar, R. (2016). Enlightened Common Sense: The Philosophy of Critical Realism (Ontological Explorations). Abingdon, Routledge.

[89] Collier, A. (1994). Critical Realism: An Introduction to Roy Bhaskar's Philosophy. London: Verson.

[90] Collier, A. (2005). Chapter 10. Philosophy and Critical Realism: Critical Realism. In: The Politics of Method in the Human Sciences Positivism and its epistemological others (Politics, History and Culture) Part 2. G. Steinmetz. (Ed.), pp. 327-345. Durham, NC: Duke University Press.

[91] Haynes, R.B. (2002). What kind of evidence is it that Evidence-Based Medicine advocates want health care providers and consumers to pay attention to? BMC Health Services Research 2, 3.

[92] Sackett, D.L., Rosenberg, W.M., Gray, J.A., Haynes, R.B. \& Richardson, W.S. (1996). Evidence based medicine: what it is and what it isn't. British Medical Journal 312 (7023) 71-72.

[93] Kirkengen, A.L. (2018). From wholes to fragments to wholes - what gets lost in translation? Journal of Evaluation in Clinical Practice 24 (5) 1145-1149.

[94] Pârvan, A. (2018). The mind electric: challenges to clinical categories from a person-centred perspective and the possibilities of metaphysics and art for clinician, patient, and treatment. Journal of Evaluation in Clinical Practice 24 (5) 1065-1078.

[95] Wakefield, A.J., Murch, S.H., Anthony, A. et al. (1998). Ileal-lymphoid-nodular hyperplasia, non-specific colitis, and pervasive development disorder in children. Lancet 351, 637-641. [Article retracted].

[96] Godlee, F., Smith, J. \& Marcovitch, H. (2011). Clear evidence of falsification of data should now close the door on this damaging vaccine scare. British Medical Journal 342, c7452.

[97] US Centers for Disease Control. (2020). Measles Cases and Outbreaks. Available at: https://www.cdc.gov/measles/cases-outbreaks.html. Accessed 26 February 2020.

[98] European Centre for Disease Prevention and Control. (2018). Available at: https://ecdc.europa.eu/en/newsevents/measles-outbreaks-still-ongoing-2018-and-

fatalities-reported-four-countries. Accessed 26 February 2020.

[99] Laboissière, P. (2018). Brazil pediatricians warn about polio outbreak in Venezuela. Available at: http://agenciabrasil.ebc.com.br/en/saude/noticia/201806/brazil-pediatricians-warn-about-polio-outbreakvenezuela.

[100] Porter, J. \& Jick, H. (1980). Addiction Rare in Patients Treated With Narcotics (Letter). New England Journal of Medicine 302 (2) 123.
[101] Van Zee, A. (2009). The Promotion and Marketing of OxyContin: Commercial Triumph, Public Health Tragedy. American Journal of Public Health 99, 221-227.

[102] US Centers for Disease Control (2017). Available at: https://www.cdc.gov/drugoverdose/data/prescribing.html. Accessed 26 February 2020.

[103] Polanyi, M. (1967). The Tacit Dimension. New York: Anchor Books.

[104] Polanyi, M. (1968). Life’s Irreducible Structure. Science 160, 1308-1312.

[105] Watson, J.D. \& Crick, F.H.C. (1953). Molecular Structure of Nucleic Acids: A Structure for Deoxyribose Nucleic Acid. Nature 171, 737-738.

[106] Wyer, P.C. (2018). The Tree of Wisdom: Maintaining epistemological health within an (emerging) evidence-free environment. European Journal for Person Centered Healthcare 6 (3) 485-491.

[107] Norman, G.R. \& Schmidt, H.G. (2000). Effectiveness of problem-based learning curricula: theory, practice and paper darts. Medical Education 34, 721-728. [108] Patel, V.L. \& Groen, G.J. (1986). Knowledge Based Solution Strategies in Medical Reasoning. Cognitve Science 10, 91-116.

[109] Loughlin, A.J. (1998). Alienation and Value Neutrality. Aldershot: Ashgate.

[110] Balint, E. (1969). The possibilities of patientcentered medicine. Journal of the Royal College of General Practitioners 17, 269-276.

[111] Balint, M. (1964). The Doctor, His Patient and the Illness, 2nd Edition. London: Churchill Livingstone.

[112] Levenstein, J.H., McCracken, E.C., McWhinney, I.R., Stewart, M.A. \& Brown, J.B. (1986). The Patientcentred Clinical Method. 1. A Model for the DoctorPatient Interaction in Family Medicine. Family Practice 3, 24-30.

[113] Wyer, P.C., Silva, S.A., Post, S.G. \& Quinlan, P. (2014). Relationship-centred care: antidote, guidepost or blind alley? The epistemology of 21st century health care. Journal of Evaluation in Clinical Practice 20, 881-889.

[114] Gabbay, J. \& Le May, A. (2004). Evidence based guidelines or collectively constructed "mindlines?" Ethnographic study of knowledge management in primary care. British Medical Journal 329, 1-5.

[115] Gabbay, J. \& Le May, A. (2011). Practice-Based Evidence for Healthcare: Clinical Mindlines. Oxford: Routledge.

[116] Gabbay, J., Le May, A., Connell, C. \& Klein, J.H. (2014). Skilled for Improvement? In: The Health Foundation

117. Martin, M. J. C. (1994) Managing Innovation and Entrepreneurship in Technology-based Firms. New York: Wiley \& Sons.

[118] Prewitt, K. (2009). Evidence-based policy: the misleading metaphor. In: The Future of Public Health, Alumni Auditoriam, Columbia University Medical Center. [119] Rosenfeld, R.M. \& Wyer, P.C. (2018). StakeholderDriven Quality Improvement: A Compelling Force for Clinical Practice Guidelines. Otolaryngology-Head and Neck Surgery 158, 16-20. 